\title{
OS OBSTÁCULOS AO EXERCÍCIO DA JURISDIÇÃO CONSTITUCIONAL E A SAÍDA DADA PELAS AUDIÊNCIAS PÚBLICAS
}

\section{THE OBSTACLES TO THE EXERCISE OF CONSTITUTIONAL JURISDICTION AND THE WAY GIVEN BY THE PUBLIC HEARINGS}

\author{
Bernardo Camargo Burlamaqui*
}

\begin{abstract}
Resumo: O presente artigo analisa a contribuição do neoconstitucionalismo ao exercício do controle de constitucionalidade realizado pelo Supremo Tribunal Federal (STF) a partir de duas de suas principais características: a força normativa do texto constitucional e a constitucionalização do direito. Partindo da teoria do neoconstitucionalismo explorada por Luís Roberto Barroso, investiga-se as dificuldades, de caráter científico e político, que se apresentam na jurisdição constitucional como consequências do robustecimento da Constituição, que deixa de ser mero documento político e passa a ser importante instrumento jurídico. A pesquisa é qualitativa e recorre a alguns pontuais julgados do STF, marcados pela convocação de audiências públicas, a fim de analisar como tal mecanismo serve aos Ministros da Corte, já que cada vez mais decidem eles sobre matérias das quais não possuem costume de se ocupar. Além de avaliar as audiências públicas como mecanismo para tentar se superar a falta de conhecimento científico sobre determinados temas, avaliar-se-á, do mesmo modo, como são elas convocadas para que obstáculos políticos sejam ultrapassados, especialmente em processos de grande repercussão em que se questiona se o Supremo Tribunal Federal, enquanto casa do Poder Judiciário, teria a verdadeira legitimidade para decidir.
\end{abstract}

Palavras-chave: Neoconstitucionalismo. Controle de constitucionalidade. Audiências públicas. Supremo Tribunal Federal.

Abstract: The present paper analyses the new constitutionalism 's contribution to the judicial review realized by the Federal Supreme Court (STF), from two of its de essential features: the normative force of the constitutional text and the law's constitutionalization. Starting from the new constitutionalism 's theory explored by Luís Roberto Barroso, investigated the difficulties, of scientific and political feature, that are present in judicial review as consequences of the Constitution 's reinforcement, that makes the Constitution not only a political document, but also an important legal instrument. The search is qualitative and resorts of some punctual judgements of STF, marked by the convocation of public hearings, in order to analyse how this mechanism serves to the Court's Justices, since they are increasingly deciding about matters of which they are not constantly aware. Besides evaluate the public hearings as a mechanism that attempts to overcome the lack of scientific knowledge about some themes, it is investigated, at the same way, how they are called, with the intention to surmount political obstacles to be trespassed,

\footnotetext{
* Graduando em Direito pela Faculdade Nacional de Direito da Universidade Federal do Rio de Janeiro (FND/UFRJ) e pesquisador do Observatório da Justiça Brasileira (OJB/UFRJ).
} 
especially in processes that have big repercussions, in wich it is questioned if the Federal Supreme Court, as the house of the Judiciary, would have legitimacy to decide.

Keywords: New constitutionalism. Judicial review. Public hearings. Federal Supreme Court. 


\section{INTRODUÇÃO}

É simbólico que uma das primeiras e mais importantes obras sobre o que se trata como neoconstitucionalismo seja chamada de "Neoconstitucionalismo(s)" (CARBONELL, 2003), com a flexão de número destacada, dando a entender que pode ser mais de um o significado da palavra que designa um dos mais em voga movimentos constitucionais.

Não é, entretanto, pretensão deste texto que sejam abordadas as distintas perspectivas do que deveria ou não ser considerado o neoconstitucionalismo. O que este escrito se propõe a fazer é, em realidade, uma breve avaliação de algumas das características que são elencadas como típicas desse novo matiz teórico, e comuns a diferentes concepções do que seria essa corrente, notadamente a força normativa do texto constitucional e a constitucionalização do direito (BARROSO, 2005).

Em momento posterior, será realizada uma breve apresentação de elementos científicos e políticos que podem interferir no exercício da jurisdição constitucional, mais especificamente atuando como óbices à operação do controle de constitucionalidade pelo Supremo Tribunal Federal. Serão expostos os obstáculos científicos que o STF enfrenta ao ter de decidir acerca de matérias altamente técnicas, sobre as quais não possui domínio, e os obstáculos políticos que se apresentam à Corte, sobretudo em se tratando de temas de grande repercussão e que se mostram essencialmente delicados à sociedade.

Será feita, finalmente, uma exibição do mecanismo das audiências públicas, usado recorrentemente por alguns Ministros do Supremo, que pode servir como alternativa a esses obstáculos, tanto os de natureza científica quanto os de natureza política, que se colocam. Por fim, serão utilizados alguns processos como pontos de referência para a discussão proposta, a fim de que não fiquem os pensamentos em um elevado nível de abstração sem quaisquer demonstrações concretas.

\section{NEOCONSTITUCIONALISMO E CONTROLE DE CONSTITUCIONALIDADE}

\subsection{A força normativa do texto constitucional}


Embora a já citada dificuldade de se definir o neoconstitucionalismo, por serem diversas as suas concepções, tem-se algumas características comuns aos discursos dos estudiosos sobre o assunto (SARMENTO, 2009, p. 115).

Como uma dessas principais características, ou, ainda, como um dos principais elementos que constituem o neoconstitucionalismo enquanto nova referência teórica, é de se destacar a ideia de que a Constituição deixa de ser mero documento político, que guiaria as decisões prospectivas de uma nação, e adquire status de norma jurídica (BARROSO, 2005, p. 07).

A Constituição, que antes se mostrava como uma carta essencialmente política, passa a deter de força normativa, isto é, passa a pertencer ao mundo jurídico, integrando-o, e, mais do que isso, regendo-o, fato este que se mostra com ainda maior impacto no modelo de supremacia constitucional, vigente no Brasil, isto é, a Constituição não só se insere no campo normativo, mas também o define, já que é, nesse modelo, a Constituição que determina e sujeita o ordenamento jurídico, e não o contrário.

Nas palavras de Luís Roberto Barroso (2005, p. 7):

[...] passou a ser premissa do estudo da Constituição o reconhecimento de sua força normativa, do caráter vinculativo e obrigatório de suas disposições. Vale dizer: as normas constitucionais são dotadas de imperatividade, que é atributo de todas as normas jurídicas, e sua inobservância há de deflagrar os mecanismos próprios de coação, de cumprimento forçado.

O Poder Judiciário passou a ter de considerar os preceitos, direitos e deveres consagrados na Constituição como um parâmetro para as suas decisões, bem como teve de observá-la o Poder Legislativo para exercer suas funções. Não se deve pensar, entretanto, que isso não ocorreu em momentos anteriores na história do Brasil. A Constituição regia, naturalmente, os trabalhos dos Poderes e já havia a previsão de realização de controle de constitucionalidade por parte do Supremo Tribunal Federal ${ }^{1}$.

\footnotetext{
${ }^{1}$ Inspirado pelos ideais republicanos dos Estados Unidos da América, Rui Barbosa capitaneou a redação da Constituição, que, além da mesma forma de governo, adotou, também, o mesmo sistema político dos norte-americanos. No bojo dessa adesão de institutos, mecanismos notadamente ligados ao EUA foram introduzidos no ordenamento jurídico brasileiro, a exemplo do Impeachment e do próprio controle de constitucionalidade, a fim de que tanto a República como o Presidencialismo fossem preservados. Nesse sentido, veja Mendes (1990).
} 
O fato é que, com a saída do país de um regime ditatorial e com a promulgação da Constituição da República Federativa do Brasil, em 1988, aquilo que antes era posto apenas como maneira formal de se estabelecer a organização dos Poderes passou a ser enfrentado de outra maneira, já que a Carta Constitucional ganha outros sentidos, sobretudo os de limitar o exercício do Poder e os de conferir direitos e garantias fundamentais a todos os indivíduos².

A questão pode ser simplificada quando fica compreendido o novo papel que ganha a Constituição Federal, especialmente após o processo de redemocratização. Adquirindo status de norma, adquire também a Constituição a força normativa que a uma norma é inerente e, portanto, seu caráter impositivo, vinculando todos os atos normativos que compõem o restante do ordenamento jurídico, e sancionando aquelas condutas que a contrariem.

\subsection{A constitucionalização do direito}

A constitucionalização do direito, especialmente a constitucionalização do direito infraconstitucional (BARROSO, 2005, p. 26) deve ser vista à luz da normatividade adquirida pelo texto constitucional. A Constituição, a partir do momento em que passa a ser dotada de supremacia material, integra o centro do sistema jurídico (BARROSO, 2005, p. 26), fazendo, assim, com que todo o direito que dela não emane, tendo como fonte diplomas legais infraconstitucionais, a ela se submeta.

Os mais variados ramos do direito, de âmbito público e de âmbito privado, passaram, assim, a ter de se adequar às normas e, principalmente, aos princípios e valores consagrados pela Constituição de 1988. Toda interpretação jurídica, em um cenário de supremacia constitucional não apenas formal, mas também material, é, assim, uma interpretação constitucional (BARROSO, 2005, p. 27).

Interpretar o Código Civil, por exemplo, seria interpretar também a

\footnotetext{
2 Nesse sentido, ao assegurar direitos civis, sociais, políticos, entre outros, elencando-os como direitos fundamentais expressamente previstos, o texto constitucional impossibilita que eles deixem de ser aplicados a qualquer caso concreto. O que pode ocorrer, e apenas quando se estiver diante de situação de colisão de alguns desses direitos, é a gradação em sua aplicação, isto é, eles nunca poderão deixar de ser aplicados, mas poderão ser menos aplicados em favor de uma maior aplicação de outros. Está é a lição de Robert Alexy (2008), que introduz a ponderação como método de decisão.
} 
Constituição, já que o que consta do texto de qualquer codificação infraconstitucional não pode estar em desacordo com aquilo que é pela Carta Constitucional estabelecido.

Nesse sentido, segundo as conclusões de Luís Roberto Barroso (2005, p. 28):

[...] a Constituição figura hoje no centro do sistema jurídico, de onde irradia sua força normativa, dotada de supremacia formal e material. Funciona, assim, não apenas como parâmetro de validade para a ordem infraconstitucional, mas também como vetor de interpretação de todas as normas do sistema.

É esse estabelecimento da Constituição como parâmetro que configura a verdadeira constitucionalização do direito. Se um ato normativo contraria o texto constitucional, ele é inválido, mas, se em conformidade com a Constituição, possui validade. $O$ documento, assim, passa a ser uma espécie de ponto de referência para que se diga o que é ou não direito.

\subsection{0 fortalecimento da jurisdição constitucional}

O que se costuma definir como fortalecimento da jurisdição constitucional acaba se mostrando, em boa parte, como uma clara consequência do papel que a Constituição de 1988 passou a desempenhar. Ora, se detém tal documento de força normativa, e se todas as normas infraconstitucionais devem estar em conformidade com a Carta Constitucional, é mais do que possível que questões de ordem constitucional passem a ser judicializadas com mais frequência.

O fato é que, se a Constituição, hoje, passa a ser considerada norma, é esperado que seja, também, a Constituição fonte de confrontos jurídicos. Nesse sentido, sabendo-se que mais frequentes serão, por conseguinte, os conflitos que envolvem a Constituição, deve-se compreender que cada vez mais a jurisdição constitucional, exercida, sobretudo pelo Supremo Tribunal Federal (PEREIRA, 2016), que realiza o controle de constitucionalidade concentrado, se constituirá como uma esfera de debates jurídicos de grande importância para a sociedade.

Sendo a Constituição de 1988 um documento que prevê inúmeros direitos aos cidadãos brasileiros, vê-se que a possibilidade de judicialização está distante de ser reduzida (PEREIRA, 2016, p. 141). O Supremo Tribunal Federal, como guardião 
da Constituição, passa, assim, a figurar polo de grande importância na sociedade brasileira como um todo, já que os Ministros que compõem a Corte decidem questões de diversas ordens, desde imbróglios tributários até regramentos relacionados à harmonização entre os Poderes ${ }^{3}$.

\section{OBSTÁCULOS CIENTÍfICOS E POLÍticos AO EXERCÍcIO DA JURISDIÇÃO CONSTITUCIONAL}

Ocorre que, além de ficar evidente a importância da atuação do Supremo Tribunal Federal, com principal atenção ao exercício do controle de constitucionalidade, para um amadurecimento constitucional, republicano e federativo, ficam evidentes, também, as incapacidades institucionais da Corte que passa, cada vez mais, a decidir sobre matérias que envolvem outras ciências que escapam ao mundo jurídico.

Os Ministros têm, assim, cada vez mais, de decidir sobre matérias sobre as quais não conhecem. Questões muito técnicas chegam ao STF, fazendo com que Ministros que, apesar de formação jurídica muito qualificada, precisem investigar novos campos científicos para que possam de se debruçar sobre lides constitucionais (CAMARGO, 2016).

É isso o que chamo, aqui, de obstáculos científicos (ou epistemológicos) ao exercício da jurisdição constitucional. Algumas matérias necessitam, por natureza, de mais esclarecimentos que não aqueles que o direito provê. É uma questão que, antes de ser jurídica, é epistemológica, porque os primeiros desafios enfrentados pelos juízes do Supremo não são desafios referentes à apreciação do direito, mas sim questões de conhecimento.

Diante de casos ligados à área médica, por exemplo, um Ministro não teria, em essência, como dizer se determinada substância que compõe um produto industrializado gera ou não gera câncer, não podendo dizer, por consequência, se tal substância deverá ser proibida tendo como base determinado dispositivo

\footnotetext{
${ }^{3}$ Vale breve destaque à obra de Ronald Dworkin (2002) que, contextualizada ao cenário dos Estados Unidos, sob a tradição jurídica da common law, e portanto mais ligada à vinculatividade dos precedentes, chama a atenção para o papel do juiz de um modo geral, não apenas daqueles que ocupam cadeiras em Cortes Constitucionais. O juiz Hércules, como chama, que é aquele que vai em busca do direito das partes, passa a ter maior espaço no Brasil com a valorização da ordem constitucional, exatamente pelo fortalecimento do poder jurisdicional.
} 
constitucional que proíba a venda de produtos industriais que contenham substâncias cancerígenas.

Pode parecer esdrúxulo pensar em casos assim, como este exemplo colocado, mas não são raras as vezes em que os Ministros se veem em debates desta ordem. Ao tratarmos do exercício da jurisdição constitucional por via do controle de constitucionalidade, estamos tratando, também, de todos os assuntos que são pela Constituição abrangidos e, portanto, de variadas matérias que podem encontrar seu cerne em ciências estranhas ao direito.

O controle de constitucionalidade exercido pelo STF não encontra, todavia, óbices apenas em se tratando de questões técnicas que exigem além de conhecimentos jurídicos. Mesmo em questões essencialmente ligadas ao direito, o Supremo Tribunal Federal enfrenta alguns obstáculos. Não se trata, nessa ordem, de obstáculos ligados ao conhecimento científico detido pelos Ministros, e sim a sua legitimidade de atuação.

Muito se debate sobre o papel do Poder Judiciário como promotor de políticas públicas ou sobre se é ou não o STF o espaço adequado para se desenvolver teses jurídicas que atendam a direitos fundamentais de grupos minorizados (PEREIRA, 2014, p. 345). A possibilidade de onze juízes, que não são, como os parlamentares, eleitos, poderem simplesmente invalidar uma norma, já é de se fazer pensar acerca das discussões que se travam sobre a legitimidade de determinadas decisões judiciais.

A grande questão é que há, em última instância, um elemento fundamental dos regimes democráticos que parece ser afastado do foco dos debates: a própria noção do que é democracia. Se, por um lado, tem-se aqueles que acreditam não ser dotado de legitimidade o Judiciário para declarar normas inconstitucionais afirmam que a democracia é ignorada quando uma norma votada e aprovada por dezenas de parlamentares, que, por sua vez, representam milhares, ou até milhões, de cidadãos brasileiros, é invalidada por onze Ministros nomeados ao cargo (BARROSO, 2015, p. 44), por outro, há aqueles que defendem que o Poder Judiciário, sobretudo o STF, enquanto guardião da Constituição, não só tem legitimidade democrática para atuar contramajoritariamente como tem esse dever, para que a própria democracia seja reafirmada e fortalecida, com base na tutela de direitos de grupos minorizados frente 
a maiorias pré-estabelecidas (BARROSO, 2015, p. 44).

Por mais que possa parecer, não se trata de uma matéria exclusivamente conceitual, mas se esbarra, também, em entraves teóricos que fazem se crer legítima ou não a atuação de juízes em tribunais constitucionais. Esses embates teóricos, que geram tantas discussões sobre o tema, não serão aqui abordados, mas há que se marcar que a jurisdição constitucional, no exercício do controle de constitucionalidade, ainda enfrenta muita resistência por uma perspectiva que enfrento, aqui, como sendo uma concepção que gera, como consequências, obstáculos políticos ao exercício do controle de constitucionalidade.

\section{A RESPOSTA DADA PELAS AUDIÊNCIAS PÚBLICAS}

Diante de tais obstáculos, das ordens científico-epistemológica e política, que se impõem no exercício do controle de constitucionalidade, surgem inúmeras alternativas com o objetivo de se tornar as decisões do Supremo Tribunal Federal menos ilegítimas por uma perspectiva democrática e mais refinada em relação à incidência de outras áreas de conhecimento científico.

Trata-se, aqui, fundamentalmente, de uma das alternativas acolhidas pelo legislador e positivadas no ordenamento jurídico brasileiro: a realização de audiências públicas. $O$ instituto das audiências públicas, que encontra amparo legal na Lei no 9.868 de 1999 e no Regimento Interno do STF, evidencia bastante sua finalidade inicial, a de permitir a superação dos obstáculos científicos encontrados na jurisdição constitucional. Fica esse intuito especialmente marcado quando se vê que as hipóteses em que podem ser as audiências públicas convocadas pelo Ministro relator de um processo se baseiam na necessidade de "esclarecimento de matéria ou circunstância de fato" (BRASIL, 1999), que seja fundamental à decisão a ser tomada.

Surge o dispositivo que regula as audiências públicas, assim, com o demonstrado objetivo de suprir as deficiências científicas estranhas ao direito, possibilitando que questões de especificidade técnica possam ser devidamente compreendidas pelos Ministros que poderão, a partir de então, decidir com menos incertezas diante de fatos científicos.

Há, entretanto, outra utilização aplicada ao instituto das audiências públicas, 
que deixam de ser simples mecanismo para se alcançar o conhecimento necessário à decisão, aproximando-se da ideia de que as oitivas também são úteis para que as decisões por ela precedidas adquiram certo grau de legitimidade democrática (MASSADAS; SANTOS; HERDY, 2016).

As audiências públicas deixam de se constituir como mero instrumento para superar a capacidade dos Ministros sobre temas aos quais eles não dominam e acabam por se tornar, da mesma maneira, uma ferramenta de democratização do Supremo Tribunal Federal.

Nessa seara, tem-se que a jurisdição constitucional, em sede de audiências públicas, abre-se à sociedade, uma vez que o Supremo, antes de julgar a questão à Corte levada, propõe-se a ouvir representantes da sociedade civil sobre o tema a ser julgado (BOLZAN DE MORAIS; SALDANHA; ESPÍNDOLA, 2011, p. 208).

É a partir desse entendimento que se faz possível concluir que, apesar de as audiências públicas terem sido estabelecidas com a finalidade de superar o que se apresenta como obstáculos científico-epistemológicos à jurisdição constitucional, elas também desenvolveram o condão de gerar maior aceitabilidade às decisões. Daí o porquê de se dizer que ganharam as audiências públicas a capacidade de superar o que se demonstra como obstáculos políticos ao controle de constitucionalidade por parte do STF, uma vez que o Tribunal se empenha na indagação de questões que gerem certa comoção (BOLZAN DE MORAIS; SALDANHA; ESPÍNDOLA, 2011, p. 208) e que envolvam considerável repercussão social.

Para que se compreenda melhor esta questão, é interessante que se dê alguns exemplos. Na Ação de Descumprimento de Preceito Fundamental de número 101 - ADPF 101 (BRASIL, 2009), os Ministros do Supremo Tribunal Federal tiveram de se debruçar sobre a constitucionalidade da norma que proíbe a importação de pneus usados, prática desempenhada por significativo setor da economia em alguns estados brasileiros. A Ministra Cármen Lúcia, relatora, convocou audiências públicas.

Elementos fundamentais de toda a discussão foram os fatos de haver ou não como descartar os pneus de modo sustentável, e da queima desse material gerar ou não substâncias cancerígenas. Nota-se, nesta situação, que o conflito jurídico entre livre iniciativa, direito ao meio ambiente equilibrado e direito à saúde não se bastava para que a decisão pudesse estar em conformidade com a realidade, marcando-se 
como necessário também o conhecimento de como se daria a queima de pneus, fazendo-se extremamente importante saber se tal processo seria ou não prejudicial à saúde e ao meio ambiente, o que fez com que a Ministra recorresse a especialistas para superar os obstáculos científicos do caso e decidir conforme seu próprio conhecimento jurídico, a partir de fatos finalmente esclarecidos.

É pertinente que se coloque, então, o que é por Júlia Massadas, Fabiana de Almeida Maia Santos e Rachel Herdy (MASSADAS; SANTOS; HERDY, 2016, p. 334) lecionado:

[...] as audiências públicas no Supremo Tribunal Federal possuem um caráter ambivalente. Os experts vão até a Corte não apenas para tratar de questões técnico-científicas, mas, também, para trabalhar questões valorativas que deveriam ser debatidas pelos próprios ministros no plenário [...] Sendo assim, elas têm tanto um caráter fático quanto valorativo.

O caráter fático e valorativo de que as autoras tratam são, respectivamente, os posicionamentos científico e político a que este texto se refere, isto é, os especialistas que vão às audiências públicas acabam por desempenhar o papel de esclarecer circunstâncias de fato aos Ministros, dando-lhes subsídios para que os obstáculos científicos sejam superados, e de legitimar, democraticamente, as decisões do STF, já que participam os expositores, enquanto membros da sociedade civil, do processo decisório como um todo.

Seguindo esse raciocínio, cabe, aqui, mais um exemplo, que se afasta mais da discussão que, em primeiro plano, mostra-se como puramente técnica, travada na ADPF 101, mas que ainda depende de conhecimentos científicos que não os exclusivamente do campo do direito e que, dessa maneira, demonstram como as audiências públicas se constituem como um mecanismo de duas finalidades.

No julgamento da ADPF 54 (BRASIL, 2012), acerca da possibilidade jurídica da interrupção de gravidez no caso de fetos anencéfalos, o Ministro Marco Aurélio, relator, optou por convocar audiências públicas, que, realizadas, demonstraram a necessidade de o Supremo Tribunal Federal conhecer se, cientificamente, um feto anencéfalo, após nascimento, teria sobrevida, isto é, se haveria ou não, neste caso, vida. Tal questão, essencialmente científica, se analisada apenas por este lado, mostrava-se fundamental à decisão, já que o que a tipificação da prática de aborto 
enquanto crime visa a tutelar é exatamente o bem jurídico da vida.

O fato é que, sabemos, um tema tão delicado como é o do aborto, não foi enfrentado apenas cientificamente. O Supremo Tribunal Federal não presenciou apenas exposições de técnicos e cientistas de renome na área, ouvindo membros de toda a sociedade civil, inclusive entidades religiosas e Ministros de Estado. $\mathrm{O}$ que se deve avaliar, nesse exemplo, é que o STF se utilizou de uma mesma ocasião para sanar dúvidas científicas em relação ao assunto principal do processo e para, ao mesmo tempo, dotar sua decisão de legitimidade democrática, uma vez tendo sido ouvida parcela interessada da sociedade civil.

Isso só comprova a ideia inicial de que, a despeito do que podem alguns autores compreender, as audiências públicas não são unicamente científicas ou unicamente políticas. Pelo contrário, não se pode falar em audiências públicas ignorando seu duplo caráter.

Foram trazidos, aqui, já dois exemplos. O primeiro referia-se a uma questão fundamentalmente científica. O segundo, por sua vez, é abrangido pelas duas funções das audiências públicas, a científica e a política. Já o terceiro, pretende-se basear essencialmente na superação de obstáculo político que se dá por meio desse mesmo instituto.

No julgamento da Ação Direta de Inconstitucionalidade de número 4.815 ADI 4815 (BRASIL, 2015), como objeto central da discussão estava a exigibilidade de autorização prévia para a publicação de biografias, que tinha como foco o conflito entre os direitos à intimidade e à liberdade de expressão. $O$ processo, que envolvia dois dos direitos individuais mais consagrados mundo afora, não demonstrava uma exata questão científica passível de dúvidas ou questionamentos. Diferentemente do que se demonstrava nos casos anteriores, em que havia verdadeiros e nítidos obstáculos científicos (se produziria ou não substâncias cancerígenas a queima de pneus e se fetos anencéfalos teriam sobrevida após seu nascimento), não parecia haver maiores complicações em relação ao julgamento das biografias não autorizadas.

Ficou isso confirmado pelos votos dos Ministros, que se socorreram do que havia sido pelos expositores das audiências públicas muito raramente. A questão, de cunho muito mais jurídico do que as outras neste texto apresentadas, pareceu, 
assim, amparar-se nas audiências públicas com a principal função de o Supremo Tribunal Federal ter sua decisão dotada de legitimidade democrática, escapando, significativamente, da questão científica, que é o que, pelo menos de acordo com o disposto legalmente, marcaria a necessidade de se utilizar tal instrumento.

Assim, nota-se como s audiências públicas se mostram um mecanismo dúplice. Sua convocação não apenas permite a aquisição de conhecimento técnicocientífico, para que sejam rompidas barreiras epistemológicas, mas também o alcance de algum grau, mesmo que pequeno, de legitimidade democrática, pela oitiva de membros da sociedade civil.

\section{CONCLUSÃO}

Com a promulgação da Constituição Federal de 1988, passou-se, no Brasil, a consagrar valores e princípios que antes não se mostravam fortemente presentes no ordenamento jurídico do país. Mais do que isso, com base no que teóricos e estudiosos do direito desenvolveram como sendo algumas das interpretações do que viria a ser denominado de neoconstitucionalismo, pode-se dizer que tais valores e princípios passaram a ser o verdadeiro norte do direito brasileiro.

O neoconstitucionalismo, enquanto corrente de pensamento de uma nova aplicação do direito passou a ser mais recorrentemente adotado por juristas que, a partir de suas concepções, contribuíram significativamente para robustecer o estudo do direito constitucional como um todo. Dessa forma, nada mais natural do movimento de acolhimento que alguns de seus elementos tiveram por parte da comunidade jurídica.

Destacam-se, aqui, a força normativa que passou a adquirir a Constituição e todo o processo de constitucionalização do direito que se deu em decorrência do fortalecimento da Carta Constitucional como documento jurídico, além de político, somente, como fora interpretado em momentos anteriores. Mostrou-se também claro o fortalecimento da jurisdição constitucional, uma vez que passaram a ser muitos dos conflitos essencialmente constitucionais.

O fato é que nem todos os debates sobre matéria constitucional giravam em torno de aspectos exclusivamente jurídicos, o que fez com que o Supremo Tribunal 
Federal percebesse que havia a necessidade de se debruçar sobre ciências distantes daquilo que cuida o campo do direito. Ainda, não se pode ignorar a falta de legitimidade democrática que é, em primeiro relance, vista no pleno exercício do controle de constitucionalidade, assunto incessantemente debatido por estudiosos de inúmeros países.

Desse modo, mostra-se como uma alternativa, tanto aos obstáculos científicos quando aos obstáculos políticos aqui postos, o mecanismo das audiências públicas, que permite aos Ministros, julgadores, conhecer de determinadas matérias específicas, com as quais muitas vezes nem tiveram contato, e, ao mesmo tempo, possibilita que as decisões judiciais passem a ser consideradas mais democráticas a partir de uma maior participação da sociedade civil no processo decisório do STF.

\section{REFERÊNCIAS}

ALEXY, Robert. Teoria dos direitos fundamentais. 5. ed. São Paulo: Malheiros, 2008.

BARROSO, Luís Roberto. A razão sem voto: o Supremo Tribunal Federal e o governo da maioria. Revista Brasileira de Políticas Públicas, Brasília, DF, v. 5, n. 2, p. 23-50, 2015.

BARROSO, Luís Roberto. Neoconstitucionalismo e constitucionalização do direito (o triunfo tardio do direito constitucional no Brasil). Revista de Direito

Administrativo, Rio de Janeiro, v. 240, p. 1-42, 2005.

BOLZAN DE MORAIS, Jose Luis; SALDANHA, Jânia Maria Lopes; ESPÍNDOLA, Ângela Araújo da Silveira. Por uma tradução democrática do direito: jurisdição constitucional e participação cidadã. In: COUTINHO, Jacinto Miranda; FRAGALE, Roberto; LOBÃO, Ronaldo (Org.). Constituição e ativismo judicial: limites e possibilidades da norma constitucional e da decisão judicial. Rio de Janeiro: Lumen Juris, 2011. p. 197219.

BRASIL. Lei no 9.868, de 10 de novembro de 1999. Dispõe sobre o processo e julgamento da ação direta de inconstitucionalidade e da ação declaratória de constitucionalidade perante o Supremo Tribunal Federal. Brasília, DF: Presidência da República, 1999. Disponível em:

http://www.planalto.gov.br/ccivil_03/leis/L9868.htm. Acesso em: 03 nov. 2017.

BRASIL. Supremo Tribunal Federal. Ação Direta de Inconstitucionalidade 4815 ADI/DF - Distrito Federal. Ação direta de inconstitucionalidade. Arts. 20 e 21 da Lei nº. 10.406/2002 (Código Civil). Preliminar de ilegitimidade ativa rejeitada. 
Requisitos legais observados. Mérito: aparente conflito entre princípios constitucionais: liberdade de expressão, de informação, artística e cultural, independente de censura ou autorização prévia (art. $5^{\circ}$ incs. IV, IX, XIV; 220, §§ 10 e $2^{\circ}$ ) e inviolabilidade da intimidade, vida privada, honra e imagem das pessoas (art. 50 , inc. X). Adoção de critério da ponderação para interpretação de princípio constitucional. Proibição de censura (estatal ou particular). Garantia constitucional de indenização e de direito de resposta. Ação direta julgada procedente para dar interpretação conforme a Constituição aos arts. 20 e 21 do Código Civil, sem redução de texto. Relatora: Min. Cármen Lúcia, 10 de junho de 2015. Disponível em: http://www.stf.jus.br/portal/processo/verProcessoAndamento.asp?incidente=4271057. Acesso em: 20 nov. 2017.

BRASIL. Supremo Tribunal Federal. Arguição de Descumprimento de Preceito Fundamental 54 ADPF/DF - Distrito Federal. Estado. Laicidade. O Brasil é uma república laica, surgindo absolutamente neutro quanto às religiões. Considerações. Feto anencéfalo. Interrupção da gravidez. Mulher. Liberdade sexual e reprodutiva. Saúde. Dignidade. Autodeterminação. Direitos fundamentais. Crime. Inexistência. Mostra-se inconstitucional interpretação de a interrupção da gravidez de feto anencéfalo ser conduta tipificada nos artigos 124, 126 e 128, incisos I e II, do Código Penal. Relator: Ministro Marco Aurélio, 12 de abril de 2012. Disponível em: http://www.stf.jus.br/portal/processo/verProcessoAndamento.asp?incidente=2226954. Acesso em: 20 nov. 2017.

BRASIL. Supremo Tribunal Federal. Arguição de Descumprimento de Preceito Fundamental 101 ADPF/DF- Distrito Federal. Argüição de descumprimento de preceito fundamental: Adequação. Observância do princípio da subsidiariedade. Arts. 170, 196 e 225 da Constituição da República. Constitucionalidade de atos normativos proibitivos da importação de pneus usados. Reciclagem de pneus usados: ausência de eliminação total de seus efeitos nocivos à saúde e ao meio ambiente ecologicamente equilibrado. Coisa julgada com conteúdo executado ou exaurido: impossibilidade de alteração. Decisões judiciais com conteúdo indeterminado no tempo: proibição de novos efeitos a partir do julgamento. Argüição jugada parcialmente procedente. Relatora: Min. Cármen Lúcia, 24 de junho de 2009. Disponível em:

http://www.stf.jus.br/portal/processo/verProcessoAndamento.asp?incidente=241653 7. Acesso em: 20 nov. 2017.

CAMARGO, Margarida Maria Lacombe. Os fatos legislativos na jurisdição constitucional. In: CONGRESO DE FILOSOFÍA DEL DERECHO PARA EL MUNDO LATINO, 2016, Alicante. Anais [...]. Alicante: Universidad de Alicante, 2016.

CARBONELL, Miguel (Org.). Neoconstitucionalismo (s). 4 ed. Madrid: Editorial Trotta, 2009.

DWORKIN, Ronald. Levando os direitos a sério. 1 ed., São Paulo: Martins Fontes, 2002.

MASSADAS, Júlia; SANTOS, Fabiana de Almeida Maia; HERDY, Rachel. A natureza 
ambivalente das audiências públicas no Supremo Tribunal Federal. In: VIEIRA, José Ribas et al. (Org.). Diálogos constitucionais e as relações entre os Poderes: VI Fórum de Grupos de Pesquisa em Direito Constitucional e Teoria do Direito. Rio de Janeiro: Freitas Bastos, 2016. p. 326-347.

MENDES, Gilmar Ferreira. Controle de constitucionalidade: aspectos jurídicos e políticos. São Paulo: Saraiva, 1990.

PEREIRA, Jane Reis Gonçalves. O Judiciário como impulsionador dos direitos fundamentais: entre fraquezas e possibilidades. Revista da Faculdade de Direito UERJ, Rio de Janeiro, n. 29, p. 127-157, 2016.

PEREIRA, Jane Reis Gonçalves. Representação democrática do Judiciário: reflexões preliminares sobre os riscos e dilemas de uma ideia em ascensão. Revista Juris Poiesis, Rio de Janeiro, v. 17, p. 343- 359, 2014.

SARMENTO, Daniel. O neoconstitucionalismo no Brasil: riscos e possibilidades. In: SARMENTO, Daniel (Org.). Filosofia e teoria constitucional contemporânea. Rio de Janeiro: Lumen Juris, 2009. p. 113-146. 